\title{
DOZE ANOS DE ESCRAVIDÃO \\ E O PROBLEMA DA REPRESENTAÇÃO \\ DAS ATROCIDADES HUMANAS
}

\begin{abstract}
A questão da representação da violência extrema faz parte dos debates presentes na esfera pública e nos meios intelectuais e universitários desde o final da Segunda Guerra Mundial. Após o Holocausto, enquanto vários intelectuais e acadêmicos passaram a considerar a ficção como um meio adequado para representar as atrocidades humanas, outros acadêmicos e sobreviventes do Holocausto se opunham a essas representações ficcionais, insistindo nos problemas éticos colocados por elas. Theodor Adorno, por exemplo, defendeu que os testemunhos oculares são os instrumentos mais poderosos para representar de maneira exata os horrores das experiências dos campos de concentração e do genocídio. ${ }^{1}$ No entanto, sobreviventes do Holocausto como Primo Levi
\end{abstract}

F. C. De Coste e Bernard Schwartz (orgs.), The Holocaust's Ghost: Writings on Art, Politics, Law, and Education (Edmonton: University of Alberta Press, 2000), especialmente o capítulo 2, de Lawrence Douglas, "Wartime Lies: Securing the Holocaust in Law and Literature," pp.16-36. Ver também Michael Rothberg, "After Adorno: Culture in the Wake of Catastrophe," New German Critique, n. 72 (1997), pp. 45-81. e historiadores como Christopher R. Browning enfatizaram os problemas colocados pelo uso desse tipo de testemunho. Segundo eles, o desejo emocional das testemunhas poderia ofuscar a abordagem crítica necessária que os historiadores, mesmo se às vezes somente em teoria, empregam quando analisam fontes primárias. $^{2}$

Apesar dessas preocupações, tragédias como a escravidão e o Holocausto foram amplamente representadas em romances e peças de teatro. Ao longo dos últimos anos, vários filmes de Hollywood, como A lista de Schindler (1993), Amistad (1997), Amada (1998), O menino do pijama listrado (2008), Bastardos inglórios (2009) e Django livre (2012) retrataram a tragédia da escravidão, do tráfico atlântico de africanos escravizados e do Holocausto. Doze anos de escravidão (2013), ganhador do Oscar de me-

Primo Levi, The Drowned and the Saved, Nova York: Vintage International, 1989, p. 27; Christopher R. Browning, Remembering Survival: Inside a Nazi Slave-Labor Camp, Nova York: W.W. Norton \& Co., 2010, p.8. 
lhor filme em 2014, do diretor britânico Steve McQueen, é o mais recente e provavelmente o mais bem sucedido filme a tentar representar o que para muitos estudiosos e artistas faz parte da esfera do irrepresentável. Baseado no relato Doze anos de escravidão, memórias de Solomon Northup publicadas em 1853, é bem possível que uma das razões para o sucesso do filme esteja relacionada com a sugestão de Adorno sobre o poder das narrativas de testemunhas oculares. Apesar do grande número de relatos deixados por homens e mulheres escravizados nos Estados Unidos e publicados em língua inglesa, entre eles os de Frederick Douglass, Sojourner Truth, Harriet Ann Jacobs, Olaudah Equiano e muitos outros, somente agora um cineasta trouxe um desses relatos para as telas.

Doze anos de escravidão retrata fielmente as provações de Solomon Northup, tais quais foram narradas no livro homônimo de sua autoria. Filho de um ex-escravo, Northup (interpretado por Chiwetel Ejiofor) nasceu livre no estado de Nova York, em 1808, ano exato da abolição do tráfico de escravos para os Estados Unidos. Nessa época, a escravidão ainda existia naquele estado e só seria abolida bem mais tarde, em 1827. Em 1829, Northup casou-se com Anne Hampton, descrita em seu livro como uma mulher de cor que carregava em suas veias o sangue das três raças, a africana, a indígena e a branca. Juntos, os dois tiveram três filhos.
Em 1834, Northup e sua família viviam em Saratoga, também no estado de Nova York. Homem instruído, ele trabalhava em diferentes atividades. Entre outros, ele obtinha contratos para transportar madeira do Lago Champlain até Troy. Durante essas viagens, visitou Montreal e Kingston, no Canadá. Além disso, Northup também ganhava a vida como violinista. Em 1841, conheceu dois homens que o convidaram a seguir com eles até a cidade de Nova York, para apresentações com seu violino. Northup, então sem trabalho, aceitou o convite e acabou em Washington, capital dos Estados Unidos, onde a escravidão ainda era vigente. Alguns dias após chegar à cidade, Northup foi drogado, sequestrado e vendido como escravo por seus companheiros de viagem. Apesar da excepcionalidade do ocorrido, cabe salientar que outros indivíduos viveram situações semelhantes em outras sociedades escravistas das Américas, entre eles Luís Gama e outros homens, mulheres e crianças nascidos livres e escravizados no Brasil. ${ }^{3}$

Sobre escravização de indivíduos livres e reescravização de ex-escravos, ver Karl Monsma e Valéria Fernandes, "Fragile Liberty: The Enslavement of Free People in the Borderlands of Brazil and Uruguay, 1846-1866," Luso-Brazilian Review, v. 50, n. 1 (2013), pp.7-25; Keila Grinberg, "Re-escravização, direitos e justiças no Brasil do século XIX", in Silvia Lara e Joseli Mendonça (orgs.), Direitos e justiças: ensaios de história social (Campinas: Editora da Unicamp, 2006), pp.101-28; e Sidney Chalhoub, A força da escravidão, São Paulo: Companhia das Letras, 2012. 
Northup foi mantido num entreposto de escravos, localizado na Avenida Independence, $\mathrm{n}^{\circ} 800$, onde fica a atual sede da Administração Federal de Aviação, em Washington DC. Como mostra uma cena do filme, o entreposto tinha uma vista privilegiada para o Capitólio dos Estados Unidos. A partir daí, o filme apresenta uma série de elementos contrastando a vida de Northup como homem livre e respeitável —no filme e apenas no filme, os afro-americanos parecem não sofrer qualquer tipo de discriminação no estado de Nova York - e sua vida como homem escravizado. A desumanização é representada pela perda do controle dos escravos sobre seus próprios corpos. Isso é visível nas repetidas cenas de castigos físicos com chicotes, correntes, algemas e outros instrumentos de tortura. O filme também enfatiza a promiscuidade imposta aos homens, mulheres e crianças escravizados. Northup e os outros cativos mantidos com ele dormiam e tomavam banho juntos, compartilhando seus corpos nus e feridos. As cenas que retratam essas atrocidades são poderosas porque a câmera ocupa uma posição particular. Em uma das primeiras cenas no entreposto de Washington DC, quando Northup é chicoteado, a câmera é colocada perto do chão em contre-plongée. Essa estratégia de colocar a câmera na posição da vítima é empregada em outras cenas de açoitamento, tornando o espectador uma testemunha íntima dos horrores que ocorrem durante o filme.
No resto do filme, o espectador continua ocupando a posição extremamente desconfortável de testemunha ocular e cúmplice da violência extrema imposta sobre Northup (cujo novo nome, de homem escravizado, é Platt) e outros escravos. Nesse sentido, o filme é bem sucedido em mostrar as complexidades do sistema escravista, complexidades essas que também eram visíveis em países como o Brasil. Certamente, senhores e traficantes de escravos são os algozes nessa narrativa. No entanto, fica claro no filme e nas palavras de Northup, assim como nas palavras de outros escravos e ex-escravos, que a ética que permite a homens e mulheres escravizados sobreviver às experiências de extrema violência é muito diferente da ética da vida cotidiana em liberdade. Em uma cena, Northup é amarrado a uma árvore com uma corda no pescoço por um feitor e lá permanece vários minutos, que no filme parecem uma eternidade. A câmera não se move. Como em um filme de terror, o homem pendurado ocupa o primeiro plano, enquanto homens, mulheres e crianças escravizados continuam a executar normalmente suas atividades cotidianas. $\mathrm{O}$ espectador testemunha a cena de tortura sem poder fazer nada, até que, enfim, o senhor de Northup corta a corda.

Outro problema significativo e complexo, apresentado de forma magistral no filme, é a violência imposta às mulheres escravizadas. 
A maioria dessas cenas está relacionada com os anos passados por Northup em uma plantação de algodão pertencente a um homem chamado Edwin Epps (Michael Fassbender), que, além de beber muito, era extremamente violento. A escrava Patsey, interpretada por Lupita Nyong'o (Oscar de melhor atriz coadjuvante), desempenha o papel de vítima exemplar de violência e exploração sexual. Como Northup explica no relato original, Patsey tinha 23 anos e era filha de um africano trazido até Cuba em um navio negreiro. Nas palavras de Northup, Patsey era a "rainha da plantação". ${ }^{4}$ Ela era famosa como a melhor catadora de algodão na área, conseguindo colher 250 quilos de algodão por dia. Como a narrativa de Northup e como o filme também mostra, Patsey sofria mais do que qualquer outro escravo na plantação, não por deixar de fazer seu trabalho ou por se rebelar de alguma forma, mas por causa da violência sexual imposta por seu senhor e pelo decorrente ciúme de sua senhora (Sarah Paulson). Como em outras sociedades escravistas, o filme mostra a função catalisadora e nefasta das senhoras brancas (Gilberto Freyre escreveu sobre isso no Brasil). Em resposta ao comportamento de Epps, que constantemente estuprava a jovem

4 David Northup, Twelve Years a Slave: Narrative of Solomon Northup, a Citizen of New-York, Kidnapped in Washington City in 1841 and Rescued in 1853, from a Cotton Plantation Near the Red River in Louisiana, Auburn: Derby and Miller, 1853, p.188. e bela Patsey, a senhora também aterrorizava a jovem escrava. Além disso, Epps castigava Patsey só para agradar sua esposa, demonstrando a ela que não considerava a escrava alguém especial em sua vida. Em uma ocasião, Patsey deixa a plantação sem avisar e, ao retornar, é severamente açoitada. Nua, a jovem é amarrada a um tronco, e Northup é forçado pelo senhor a chicoteá-la. O que o filme não explica é que, a essa altura, Northup era feitor e já dominava com maestria a arte de chicotear outros escravos. Durante essa longa cena, a mais violenta de todo o filme, a câmera é às vezes posicionada no lugar do feitor e às vezes na posição da vítima. Depois de infligir algumas dezenas de chicotadas, Northup tenta desistir da tarefa horrível, e Epps continua a tortura até Patsey desmaiar.

Apesar de enfatizar a dinâmica complexa de terror estabelecido por um sistema em que escravos eram obrigados a punir outros escravos, o filme enfatiza a vitimização, alternando cenas de ação e cenas lentas. O cineasta usa e abusa dos close-ups para fazer do espectador um cúmplice dos horrores da escravidão. Às vezes, a violência contra os homens e mulheres escravizados parece ser totalmente gratuita, especialmente no caso de Patsey. O filme retrata a escravidão como tortura e terror, mas também deixa claro que, do ponto de vista do senhor, uma escrava em idade reprodutiva e tão eficiente como Patsey era uma propriedade precio- 
sa. Além de bonita e inteligente, ela tinha uma tremenda habilidade para colher algodão, o que gerava grandes lucros para seu senhor.

$\mathrm{O}$ filme retrata com fidelidade $\mathrm{o}$ relato de Northup. No entanto, espectadores e também estudiosos devem levar em conta que Doze anos de escravidão foi publicado no contexto do movimento abolicionista norte-americano. O livro não se destinava apenas a fornecer um retrato preciso da vida escrava, mas também tinha como objetivo promover a campanha abolicionista. Mesmo se a grande ênfase nas punições físicas apresentadas no filme é esclarecedora para a compreensão da escravidão e da violência contra os afro-americanos, que continuou e se intensificou no período pós-emancipação, esse foco coloca homens e mulheres escravizados em uma posição indefesa, negandolhes qualquer tipo de protagonismo e meios de resistir aos horrores da escravidão. Tal imagem, aliás, não é muito diferente da imagem que predomina na memória pública e coletiva da escravidão no Brasil, nos Estados Unidos, na Inglaterra e em outros países escravocratas, e que é particularmente visível em exposições sobre a escravidão em vários museus nesses países. ${ }^{5}$ Tal represen-

Ver Myrian Sepúlveda dos Santos, "Representations of Black People in Brazilian Museums," Museum and Society, v. 3, n. 1 (2005), pp.51-65; e Ana Lucia Araujo, Shadows of the Slave Past: Memory, Heritage, and Slavery, Nova York: Routledge, 2014, no prelo). tação de sofrimento e vitimização extremos contrasta com a representação dos redentores que aparecem no final do filme, quando Northup é finalmente resgatado por amigos brancos do norte. Mas, ao mesmo tempo, seria importante se ter em mente que quem nasceu escravizado e que não teve a oportunidade de ser libertado também encontrou numerosas maneiras de resistir e negociar suas vidas, mesmo vivendo sob um assombroso sistema de extrema violência. Esses homens e mulheres também foram ativos combatentes e sobreviventes, e não apenas vítimas passivas como são às vezes retratados no filme.

Doze anos de escravidão é, certamente, um marco no que tange à representação da escravidão no cinema estadunidense e mundial. A realização e a popularidade alcançada pelo filme refletem as possibilidades oferecidas pelo atual contexto norte-americano, possibilidades essas que se evidenciaram principalmente a partir de 2008, com a eleição de Barack Obama para presidente do país. No entanto, cabe lembrar que McQueen nasceu e reside na Inglaterra, país que nos últimos anos tem tomado diversas medidas para reconhecer no espaço público seu envolvimento no tráfico atlântico de escravos. Essa posição talvez tenha facilitado a tarefa de produzir o filme, já que o diretor ocupa uma posição externa ao contexto das tensões raciais existentes nos Estados Unidos. Além disso, o 
fato de a história do filme retratar a vida de um homem que nasceu livre e foi "excepcionalmente" escravizado, sem acentuar o papel crucial que teve a escravidão na totalidade do país, provavelmente seja mais aceitável para plateias majoritariamente brancas de um país onde o legado da escravidão ainda persiste, e onde o tratamento dessa questão e o reconhecimento desse passado na esfera pública ainda estão em amadurecimento e continuam a provocar polêmicas.

\section{Ana Lucia Araujo}

aaraujo@howard.edu

Howard University, Estados Unidos 